\title{
ELECTRICAL PROPERTIES OF NANOROD-BASED ZnO/SiC HYBRID HETEROJUNCTIONS
}

\author{
Stanislav TIAGULSKYI, Roman YATSKIV, Hana FAITOVÁ, Šárka KUČEROVÁ, Jan VANIŠ, \\ Jan GRYM
}

Institute of Photonics and Electronics of the Czech Academy of Sciences, Prague, Czech Republic, EU, tiagulskyi@ufe.cz

https://doi.org/10.37904/nanocon.2019.8639

\begin{abstract}
$\mathrm{ZnO}$ nanorods have attracted increasing interest in recent years due to their potential in optoelectronic applications. The lack of $\mathrm{p}$-type $\mathrm{ZnO}$ emphasizes the importance of rectifying junctions realized on other $\mathrm{p}$ type materials. $\mathrm{SiC}$ is a good candidate to create hybrid heterojunctions with $\mathrm{ZnO}$ due to its wurtzite crystal structure and a small lattice and thermal mismatch. The $\mathrm{ZnO} / \mathrm{SiC}$ heterojunctions have a potential to show intense UV electroluminescence. We investigate morphology and electrical properties of a single verticallyoriented $\mathrm{ZnO}$ nanorod on a SiC substrate. The current-voltage measurements are performed directly in the vacuum chamber of a scanning electron microscope. The contact to a single nanorod is obtained by a nanoprobe, which allows for the measurement of the current-voltage characteristic of a single nanorod heterojunction of choice. The influence of $\mathrm{ZnO}$ growth parameters and post-growth treatment of $\mathrm{ZnO} / \mathrm{SiC}$ structures are studied with the aim to minimize the density of structural/interfacial defects and to create lowdimensional hybrid heterojunctions with the potential to show intense UV electroluminescence.
\end{abstract}

Keywords: Chemical bath deposition, current-voltage characteristics, SEM, ZnO nanorods, $\mathrm{ZnO} / \mathrm{SiC}$ heterojunctions

\section{INTRODUCTION}

Zinc oxide $(\mathrm{ZnO})$ with its wide band gap of $3.37 \mathrm{eV}$ and high exciton binding energy of $60 \mathrm{meV}$ is a promising material for electronic and photonic applications. $\mathrm{ZnO}$ offers several advantages over other wide-bandgap materials: a low cost and wide availability, environmental safeness, high thermal stability, and possibility to form different kinds of nanostructures by a variety of growth techniques. As-grown $\mathrm{ZnO}$ is intrinsically n-type semiconductor and reproducible p-type doping is difficult to be achieved. Therefore, the advantageous properties of $\mathrm{ZnO}$ for light-emitting devices are frequently investigated in the form of heterostructures with other materials $[1,2]$.

Silicon carbide $(\mathrm{SiC})$ is another promising wide bandgap semiconductor material with a high thermal conductivity, high breakdown voltage, low response time, excellent mechanical properties, and good chemical stability. $\mathrm{SiC}$ is a good candidate to create hybrid heterojunctions with $\mathrm{ZnO}$ due to its wurtzite crystal structure and small lattice $(\sim 5 \%)$ and thermal $(<1 \%)$ mismatch [3,4].

Chen et al. reported $\mathrm{ZnO} / \mathrm{SiC}$ heterojunctions that were deposited by metal-organic chemical vapor deposition on n-6H-SiC [5]. The isotype heterojunctions showed rectifying characteristics with the reverse current in the picoampere range, the on/off ratio $\sim 10^{7}$, and the ideality factor $\sim 1.23$. The native $\mathrm{SiO}_{2}$ layer on $\mathrm{SiC}$ surface was reported to have impact on the morphology of the deposited $\mathrm{ZnO}$ and consequently on the electrical properties of $\mathrm{ZnO} / \mathrm{SiC}$ heterojunctions. Felix et al. reported that the heterojunctions formed by thermally deposited $\mathrm{ZnO}$ thin films on $\mathrm{n}-4 \mathrm{H}-\mathrm{SiC}$ had excellent electrical properties with the leakage current lower than $1 \mathrm{nA}$ and the rectification ratio $\approx 10^{5}$. The larger than unity ideality factor was ascribed to the thickness and composition variation of interfacial layer [6]. Taube et al. studied the electrical properties of $\mathrm{ZnO} / \mathrm{SiC}$ heterojunctions created by atomic layer deposition of $\mathrm{ZnO}$ layers on $\mathrm{n}-4 \mathrm{H}-\mathrm{SiC}$ and $\mathrm{p}-4 \mathrm{H}-\mathrm{SiC}$ substrates. The 
isotype heterojunction diodes showed better electrical properties than the anisotype diodes. In particular, lower values of ideality factor, series resistance, capacitance and built-in voltage were reported. The lower resistance and capacitance are especially important for the increase of the response time of UV photodetectors. Due to the absence of donor-acceptor pair transitions in n-type $4 \mathrm{H}-\mathrm{SiC}$, the isotype $\mathrm{ZnO} / 4 \mathrm{H}-\mathrm{SiC}$ heterojunctions showed lower response to visible light while keeping UV light response at the same level as observed for anisotype heterojunctions [7]. Rebaoui et al. reported on the effects of polytypes and doping nature on electrical properties of $\mathrm{ZnO} / \mathrm{SiC}$ heterojunctions. The $\mathrm{ZnO} / \mathrm{SiC}$ diodes based on $\mathrm{n}$-type $4 \mathrm{H}$-SiC polytype showed the best electrical performance. It was found, that the $\mathrm{ZnO} / \mathrm{n}-4 \mathrm{H}-\mathrm{SiC}$ heterojunctions had 40 times lower leakage current than the $\mathrm{ZnO} / \mathrm{p}-4 \mathrm{H}-\mathrm{SiC}$ heterojunctions and two times higher rectifying ratio than the $\mathrm{ZnO} / \mathrm{n}-6 \mathrm{H}-\mathrm{SiC}$ heterojunctions. The excellent performance of $\mathrm{ZnO} / \mathrm{n}-4 \mathrm{H}-\mathrm{SiC}$ heterojunctions was ascribed to high vertical a-axis electron mobility, higher heterojunction barrier, and suppressed trap assisted tunneling [8].

The excellent rectifying properties of isotype $\mathrm{ZnO} / \mathrm{SiC}$ heterojunctions considered above were explained in detail by Zhang et al. using x-ray photoelectron and Auger electron spectroscopies of ZnO layers deposited on $6 \mathrm{H}-\mathrm{SiC}$ substrates by molecular beam epitaxy from which the band alignment for the isotype $\mathrm{ZnO} / \mathrm{SiC}$ interface was calculated. Significant band offsets were suggested to be the reason for high rectification ratios of isotype $\mathrm{ZnO} / \mathrm{SiC}$ structures. Together with the significant band offsets, the absence of chemical interactions and additional interfacial layers on the abrupt MBE-ZnO/SiC interface was considered as the reason for highly rectifying isotype $\mathrm{ZnO} / \mathrm{SiC}$ structures [9]. On the other hand, $\mathrm{Mu}$ et al. reported the presence of the zinc silicate species at the $\mathrm{ZnO} / \mathrm{SiC}$ interface prepared by the radiofrequency magnetron sputtering. He suggested, that the interface species significantly affect the electronic structure of the $\mathrm{ZnO} / \mathrm{SiC}$ interface [10].

To summarize, the $4 \mathrm{H}$ polytype of $\mathrm{SiC}$ is more attractive for the device application due to its wider bandgap and higher mobility than other polytypes. Moreover, it is widely believed that the isotype $\mathrm{n}-\mathrm{ZnO} / \mathrm{n}-\mathrm{SiC}$ heterojunctions are more suitable for optoelectronic devices than the anisotype $\mathrm{n}-\mathrm{ZnO} / \mathrm{p}$-SiC heterojunctions.

As was mentioned above, $\mathrm{ZnO}$ easily forms several types of nanostructures that are suitable for the manufacturing of vertically stacked devices (e.g. ZnO nanorods/SiC LEDs). However, further downscaling to nanoelectronic devices requires a deep understanding of electrical properties of nanoscale heterojunctions below a single nanorod. In this work, electrical properties of a single $\mathrm{ZnO}$ nanorod on $\mathrm{n}-4 \mathrm{H}-\mathrm{SiC}$ substrates are investigated by measuring the current-voltage (I-V) characteristics. The contact to a single nanorod is obtained by a nanoprobe in the chamber of a scanning electron microscope (SEM), which allows for the measurement of the current-voltage characteristic of a single nanorod heterojunction of choice.

\section{EXPERIMENTAL METHODS}

Conventional chemical bath deposition (CBD) method was used to synthesize $\mathrm{ZnO}$ nanorods on $\mathrm{n}-4 \mathrm{H}-\mathrm{SiC}$ substrates [11]. Commercially available nitrogen doped $4 \mathrm{H}-\mathrm{SiC}$ substrates with a thickness of $350 \mathrm{~mm}$ and an electron concentration of $\mathrm{n}=10^{17} \mathrm{~cm}^{-3}$ were used for the fabrication of the $\mathrm{ZnO} / \mathrm{SiC}$ junctions. The substrate was sequentially cleaned in $\mathrm{H}_{2} \mathrm{SO}_{4}: \mathrm{H}_{2} \mathrm{O}_{2}, \mathrm{NH}_{4} \mathrm{OH}: \mathrm{H}_{2} \mathrm{O}_{2}: \mathrm{H}_{2} \mathrm{O}(1: 1: 5)$ at $70^{\circ} \mathrm{C}, \mathrm{HF}: \mathrm{H}_{2} \mathrm{O}(1: 20)$ and $\mathrm{H}_{2} \mathrm{O}: \mathrm{HCl}_{2}: \mathrm{H}_{2} \mathrm{O}_{2}$ $(6: 1: 1)$ at $70^{\circ} \mathrm{C}$. After each step, the substrate was rinsed in deionized water and dried with nitrogen. $\mathrm{A}$ backside ohmic contact was created by thermal evaporation of $150 \mathrm{~nm}$ of $\mathrm{Ni}$ and subsequently annealed at $950{ }^{\circ} \mathrm{C}$ for $10 \mathrm{~min}$ in $\mathrm{Ar}$ atmosphere [12].

The $5 \mathrm{mM}$ aqueous solution of zinc nitrate hexahydrate, which is a source of $\mathrm{Zn}^{2+}$ ions, and hexamethylenetetramine, which is a source of $\mathrm{OH}^{-}$ions, was used for the $\mathrm{CBD}$ of $\mathrm{ZnO}$ nanorods. To activate the reaction, the temperature of the solution was elevated to $95^{\circ} \mathrm{C}$ for 2 hours.

The morphology of ZnO nanorods was observed using Tescan Lyra 3 GM FIB/SEM system. The I-V characteristics of the nanoscale heterojunction formed by a single $\mathrm{ZnO}$ nanorod on $\mathrm{SiC}$ substrate were measured in the chamber of the same FIB/SEM system (Figure 1). 

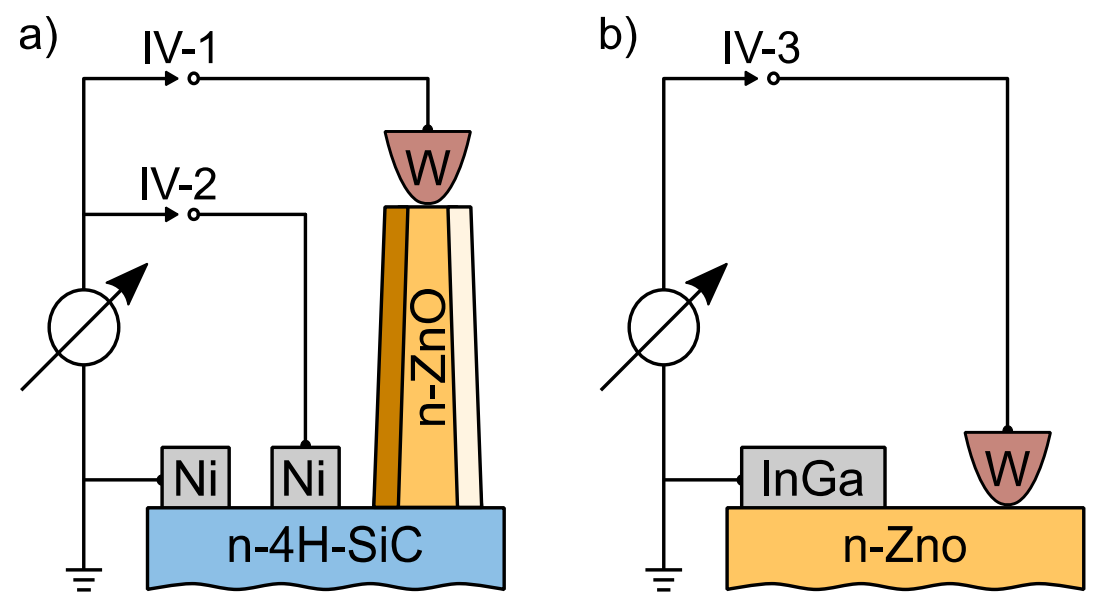

Figure 1 Schematic illustrations of the current-voltage measurements of: (a) freestanding ZnO nanorods on $\mathrm{n}-4 \mathrm{H}-\mathrm{SiC}$ substrate and $\mathrm{Ni} / \mathrm{n}-\mathrm{SiC}$ contacts; (b) W-probe on a reference n-type ZnO bulk substrate

A tungsten needle of a SmarAct nanoprobe served as a top ohmic contact. The tip of the needle was cleaned using the focused ion beam to remove native tungsten oxide. The bottom metal contact was deposited on precleaned SiC substrate by vacuum evaporation of a $150 \mathrm{~nm}$ layer of $\mathrm{Ni}$ with subsequent annealing of the substrates. The I-V characteristics were measured by applying a linear voltage sweep to the top needle contact while the bottom contact was grounded. The ohmic behavior of the metal contacts was confirmed by additional measurements (electrical circuits "IV-2" in Figure 1a for the bottom contact, electrical circuit "IV-3" in Figure 1b for the top contact).

\section{RESULTS AND DISCUSSION}

Figure 2 shows SEM images of individual nanorods grown on the n-4H-SiC substrates. The nanorods were grown randomly and their lengths and diameters had a significant dispersion. Before the electrical characterization, the samples were carefully examined in SEM to select the nanorods with equal dimensions: typical values of the length and diameter of $\mathrm{ZnO}$ nanorods were $L=14 \mu \mathrm{m}, d=1.8 / 3.5 \mu \mathrm{m}$ (top/bottom), respectively.

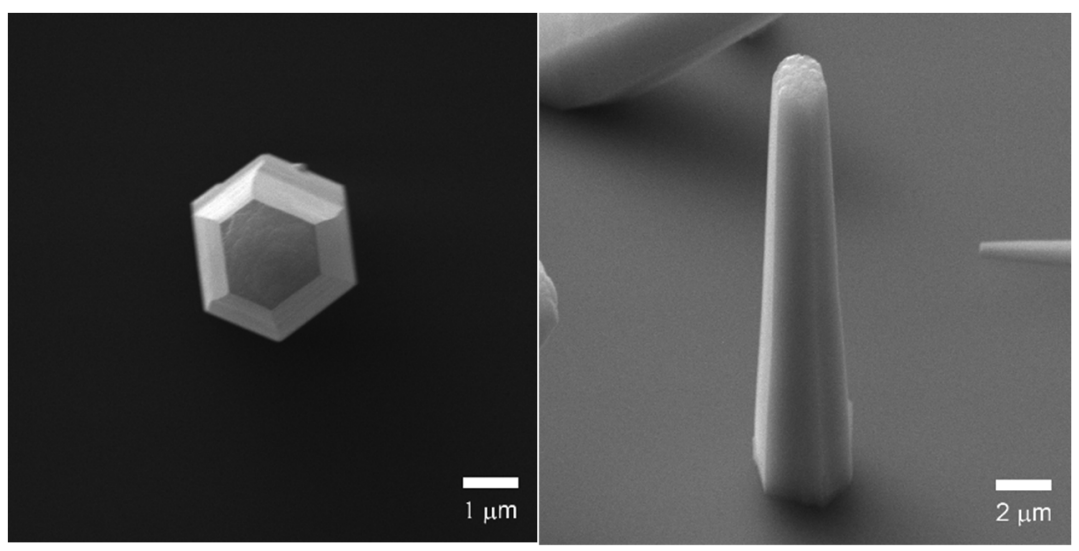

Figure 2 Top view and $55^{\circ}$ tilted view SEM images of a single $\mathrm{ZnO}$ nanorod grown on n-4H-SiC substrate

Figure 3 shows representative current-voltage characteristics (i) of the bottom Ni/SiC contact before and after thermal annealing, (ii) of the top $\mathrm{W} / \mathrm{ZnO}$ contact measured on the reference bulk hydrothermally grown $\mathrm{ZnO}$ substrate, and (iii) of the single $\mathrm{n}-\mathrm{ZnO}$ nanorod/n-4H-SiC heterojunction. 

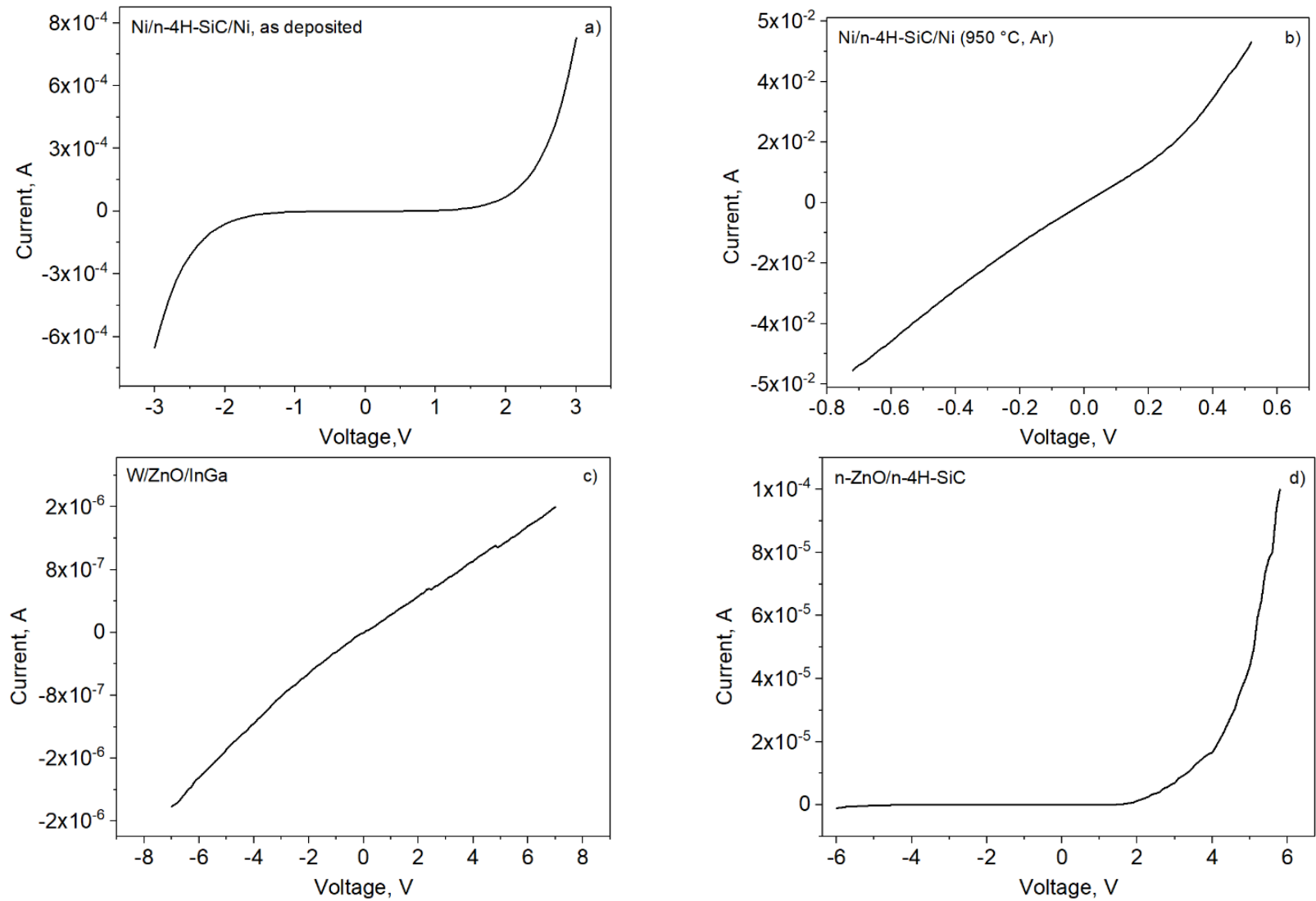

Figure 3 Experimental current-voltage characteristics. $(a, b) \mathrm{Ni}$ contact on SiC before/after annealing, (c) tungsten probe on the surface of the bulk $\mathrm{ZnO}$, (d) a single nanorod $\mathrm{ZnO} / \mathrm{n}-4 \mathrm{H}-\mathrm{SiC}$ heterojunction

Table 1 The parameters extracted from the experimental current-voltage measurements

\begin{tabular}{|c|c|c|c|}
\hline $\begin{array}{c}\text { Ion/loff at } \pm \mathbf{2 V} \\
\text { (unitless) }\end{array}$ & $\begin{array}{c}\mathbf{V}_{\text {on }} \text { (forward) } \\
\text { (V) }\end{array}$ & $\begin{array}{c}\mathbf{R} \text { w/Zno, } \\
\text { (Ohm) }\end{array}$ & $\begin{array}{c}\mathbf{R}_{\text {Ni/Sic, }} \\
\text { (Ohm) }\end{array}$ \\
\hline$\approx 40 \cdot 10^{3}$ & 1.6 & $\approx 10^{6}$ & $\approx 20$ \\
\hline
\end{tabular}

The I-V measurements between two as-deposited Ni contacts show the presence of two back-to-back Schottky diodes. However, after the thermal annealing, a clear ohmic behavior of $\mathrm{Ni} / \mathrm{SiC}$ contact was observed. The top $\mathrm{W} / \mathrm{ZnO}$ contact also demonstrates almost linear behavior. Therefore, we can suggest that the diodelike I-V characteristics of $\mathrm{n}-\mathrm{ZnO}$ nanorod $/ \mathrm{n}-4 \mathrm{H}-\mathrm{SiC}$ heterostructures are determined by the charge transport through the $\mathrm{ZnO} / \mathrm{SiC}$ interface rather than by the metal contacts. The parameters extracted from the current-voltage measurements are summarized in Table 1.

Figure 4 Schematic energy band diagram for the $\mathrm{n}-\mathrm{ZnO} / \mathrm{n}-4 \mathrm{H}-\mathrm{SiC}$ heterojunction. The unit is $\mathrm{eV}$ in all cases

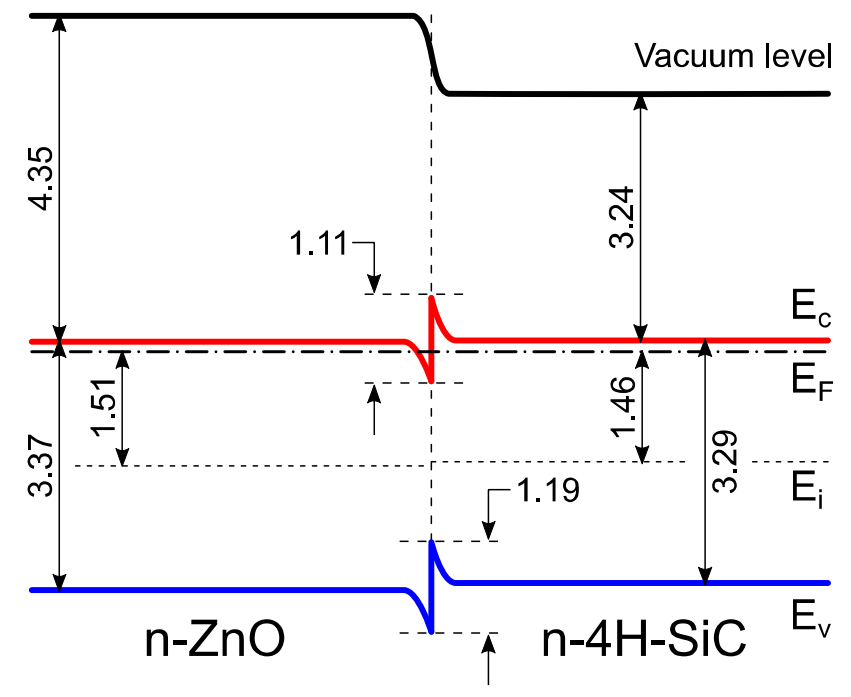


To explain the rectifying behavior of $\mathrm{n}-\mathrm{ZnO} / \mathrm{n}-4 \mathrm{H}-\mathrm{SiC}$ heterojunctions, in the first approach, the Anderson model was used to construct the $\mathrm{n}-\mathrm{ZnO} / \mathrm{n}-4 \mathrm{H}-\mathrm{SiC}$ heterojunction band diagram (Figure 4). The electron affinities of $\mathrm{ZnO}$ and of $4 \mathrm{H}-\mathrm{SiC}$ were taken as $\mathrm{XnO}=4.35 \mathrm{eV}$ and $\mathrm{Xsic}_{\mathrm{ZiC}}=3.24 \mathrm{eV}$, and the bandgap energies of $\mathrm{ZnO}$ and $\mathrm{SiC}$ as $\mathrm{E}_{\mathrm{g}, \mathrm{ZnO}}=3.37 \mathrm{eV}$ and $\mathrm{E}_{\mathrm{g}, \mathrm{SiC}}=3.29 \mathrm{eV}$, respectively.

The conduction band offset is therefore $\Delta E_{C}=X_{Z n O}-X_{S i C}=1.1 \mathrm{eV}$, while the valence band offset is $\Delta E_{V}=\left(X_{Z n O}+E_{g, \text { Zno }}\right)-\left(X_{S i c}+E_{g, \text { sic }}\right)=1.19 \mathrm{eV}$. Adjustment can be made to account for the position of the Fermi level relative to the conduction band in each material. The positions of Fermi level below the conduction band edge $E_{c}-E_{F}$ is taken from the Boltzmann's statistics assuming that all dopants are fully ionized:

$E_{C}-E_{F}=-k T \ln \frac{N_{D}}{N_{C}}$,

where, $k$ is the Boltzmann constant, $T$ is the absolute temperature, $N_{D}$ is the donor concentration and $N_{C}$ is the effective density of states in the conduction band [13].

Figures 5 shows the experimental and theoretically fitted forward bias I-V characteristic of a single nanorod $\mathrm{n}-\mathrm{ZnO} / \mathrm{n}-4 \mathrm{H}-\mathrm{SiC}$ isotype heterojunction in semilogarithmic scale. The proposed equivalent circuit of the nanoscale heterojunction (the inset in Figure 5) takes into account the current flow through the potential barrier at the $\mathrm{n}-\mathrm{ZnO} / \mathrm{n}-4 \mathrm{H}-\mathrm{SiC}$ interface; the current limited by the space charge region; the leakage current that bypasses the junction region; and the excessive serial resistance of the contacts and neutral regions of the semiconductors.

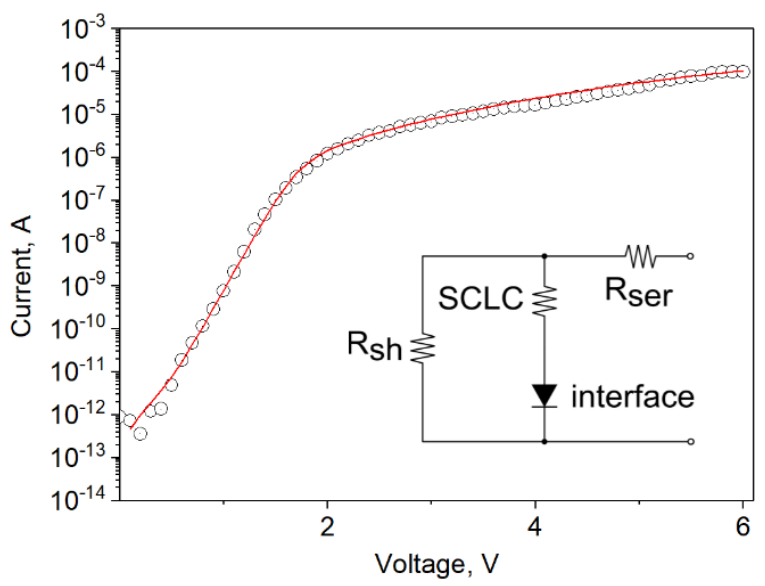

Figure 5 Experimental and theoretically fitted forward bias I-V characteristics of a single nanorod $\mathrm{n}-\mathrm{ZnO} / \mathrm{n}-4 \mathrm{H}-\mathrm{SiC}$ isotype heterojunction

In the frame of the proposed model, the current flowing through the potential barrier is given by:

$I_{1}=I_{0}\left(e^{\frac{q}{n k T}\left(V-I_{1} R_{S e r}\right)}-1\right)$

where $I_{0}$ is the reverse bias saturation current of the junction, $\mathrm{n}$ is the ideality factor of the junction, $q$ is the electron charge, $k$ is the Boltzmann's constant, $T$ is the temperature and $R_{\text {ser }}$ is the serial resistance [13].

At higher biases, when the impact of potential barrier is negligible, the current is limited by the conductance of the space charge region. In general case the space charge limited current (SCLC) is given by:

$I_{2}=A\left(V-I_{2} R_{s e r}\right)^{\beta}$

where $A$ is a coefficient that is related to the length and conductivity of the current flow path and $\beta$ is a scaling exponent of the power-law current-voltage dependence, which should be equal to 2 in the case of trap-free space charge limited current, or $>2$ in the case of traps distributed over the bandgap [14]. 
The leakage current that bypassed the heterojunction follows the Ohm's law:

$I_{3}=\left(V-I_{3} R_{s e r}\right) / R_{s h}$

where $R_{s h}$ is the shunt resistance of the leakage path.

According to the Kirchhoff's rule, the total current injected to a single nanorod $\mathrm{n}-\mathrm{ZnO} / \mathrm{n}-4 \mathrm{H}-\mathrm{SiC}$ heterojunction is:

$I=\frac{I_{1} I_{2}}{I_{1}+I_{2}}+I_{3}$

The I-V curve modelled using Equations (2) - (5) fits well experimental I-V characteristics of the single nanorod n-ZnO/n-4H-SiC heterojunction. The fitting variables are summarized in Table 2.

Table 2 The parameters extracted from the fitting of the forward bias I-V curves for the single nanorod $\mathrm{n}-\mathrm{ZnO} / \mathrm{n}-4 \mathrm{H}-\mathrm{SiC}$ heterojunction

\begin{tabular}{|c|c|c|c|c|}
\hline $\begin{array}{c}\mathbf{n} \\
\text { (unitless) }\end{array}$ & $\begin{array}{c}10 \\
\text { (A) }\end{array}$ & $\begin{array}{c}\boldsymbol{\beta} \\
\text { (unitless) }\end{array}$ & $\begin{array}{c}\text { Rsh } \\
\text { (Ohm) }\end{array}$ & $\begin{array}{c}\text { Rser } \\
\text { (Ohm) }\end{array}$ \\
\hline 3.9 & $4 \cdot 10^{-14}$ & 4 & $2.5 \cdot 10^{12}$ & $4 \cdot 10^{4}$ \\
\hline
\end{tabular}

The ideality factor larger than unity, relatively high saturation current lo, and the power law exponent larger than two allow us to consider the trap assisted tunneling process through the interface states distributed over the band gap as the main transport mechanism for the single nanorod $\mathrm{n}-\mathrm{ZnO} / \mathrm{n}-4 \mathrm{H}-\mathrm{SiC}$ heterojunction. The leakage current determined by the shunt resistance is on the order of $1 \mathrm{pA}$, which is the noise level of our measurement setup. Taking into account the experimental I-V characteristics measured on the reference bulk $\mathrm{ZnO}$ substrate (Figure 3c), a large serial resistance is ascribed to the resistance of the top W/ZnO contact and of the $\mathrm{ZnO}$ nanorod.

\section{CONCLUSIONS}

In summary, nanoscale heterojunctions between a single free-standing $n$-type ZnO nanorod grown on $\mathrm{n}-4 \mathrm{H}-\mathrm{SiC}$ substrate were obtained by chemical bath deposition. Using the nanomanipulator mounted in the scanning electron microscope, the current-voltage characteristics of individual $n-Z n O ~ n a n o r o d / n-4 H-S i C$ heterojunctions were measured. Heterojunctions showed diode-like characteristics with a high rectification ratio and low leakage current. The equivalent circuit of the isotype $\mathrm{n}-\mathrm{ZnO} / \mathrm{n}-4 \mathrm{H}-\mathrm{SiC}$ heterojunction was proposed. The parameters of the heterojunctions were extracted from the experimental current-voltage characteristics using a proposed fitting model. We believe that the method of characterization of a single nanorod-based heterojunction proposed in this paper opens door for a detailed analysis of charge transport in a variety of nanoscaled optoelectronic devices.

\section{ACKNOWLEDGEMENTS}

This work was supported by the Czech Science Foundation projects 17-00546S and 15-17044S.

\section{REFERENCES}

[1] OZGUR, U., ALIVOV, Y. I., LIU, C., TEKE, A., RESHCHIKOV, M. A., DOGAN, S., AVRUTIN, V., CHO, S. J. and MORKOC, H. A comprehensive review of zno materials and devices. Journal of Applied Physics, 2005, vol. 98, no. 4 , p. 041301.

[2] JANOTTI, A. and VAN DE WALLE, C. G. Fundamentals of zinc oxide as a semiconductor. Reports on Progress in Physics, 2009, vol. 72, no. 12, p. 126501. 
[3] MORKOC, H., STRITE, S., GAO, G. B., LIN, M. E., SVERDLOV, B. and BURNS, M. Large-band-gap sic, iii-V nitride, and ii-vi znse-based semiconductor-device technologies. Journal of Applied Physics, 1994, vol. 76, no. 3, pp. 1363-1398.

[4] CASADY, J. B. and JOHNSON, R. W. Status of silicon carbide (sic) as a wide-bandgap semiconductor for hightemperature applications: A review. Solid-State Electronics, 1996, vol. 39, no. 10, pp. 1409-1422.

[5] CHEN, Y., SARAF, G., REYES, P. I., DUAN, Z. Q., ZHONG, J. and LU, Y. C. Structural, electrical, and piezoelectric properties of zno films on sic-6h substrates. Journal of Vacuum Science \& Technology B, 2009, vol. 27 , no. 3, pp. 1631-1634.

[6] FELIX, J. F., AZIZ, M., DE ARAUJO, C. I. L., DE AZEVEDO, W. M., ANJOS, V., DA SILVA, E. F. and HENINI, M. Zinc oxide thin films on silicon carbide substrates (zno/sic): Electro-optical properties and electrically active defects. Semiconductor Science and Technology, 2014, vol. 29, no. 4.

[7] TAUBE, A., SOCHACKI, M., KWIETNIEWSKI, N., WERBOWY, A., GIERALTOWSKA, S., WACHNICKI, L., GODLEWSKI, M. and SZMIDT, J. Electrical properties of isotype and anisotype zno/4h-sic heterojunction diodes. Applied Physics Letters, 2017, vol. 110, no. 14.

[8] REBAOUI, Z., BOUIAJRA, W. B., ABID, M. A., SAIDANE, A., JAMMEL, D., HENINI, M. and FELIX, J. F. Sic polytypes and doping nature effects on electrical properties of zno-sic schottky diodes. Microelectronic Engineering, 2017, vol. 171, pp. 11-19.

[9] ZHANG, Y. F., LIN, N. Y., LI, Y. P., WANG, X. D., WANG, H. Q., KANG, J. Y., WILKS, R., BAR, M. and MU, R. The isotype zno/sic heterojunction prepared by molecular beam epitaxy-a chemical inert interface with significant band discontinuities. Scientific Reports, 2016, vol. 6.

[10] MU, R., STEIGERT, A., LIN, N. Y., WILKS, R., BAR, M. and ZHANG, Y. F. The chemical structure of the zno/sic heterointerface as revealed by electron spectroscopies. Journal of Physics D-Applied Physics, 2015, vol. 48, no. 30 .

[11] YATSKIV, R. and GRYM, J. Luminescence properties of hydrothermally grown zno nanorods. Superlattices and Microstructures, 2016, vol. 99, pp. 214-220.

[12] YATSKIV, R. and GRYM, J. Graphite/sic junctions and their electrical characteristics. Physica Status Solidi aApplications and Materials Science, 2017, vol. 214, no. 9.

[13] SZE, S. M. Physics of semiconductor devices, 3rd ed. Hoboken, NJ: John Wiley and Sons, 2007, pp. 815.

[14] TALIN, A. A., LÉONARD, F., KATZENMEYER, A. M., SWARTZENTRUBER, B. S., PICRAUX, S. T., TOIMILMOLARES, M. E., CEDERBERG, J. G., WANG, X., HERSEE, S. D. and RISHINARAMANGALUM, A. Transport characterization in nanowires using an electrical nanoprobe. Semiconductor Science and Technology, 2010 , vol. 25, no. 2, p. 024015. 